Molecules 2001, 6, 194-202

\title{
molecules
}

ISSN 1420-3049

http://www.mdpi.org

\section{7-(1-Acetoxymethylidene)Benzonorbornadiene: A Versatile Reagent for the Synthesis of 7-Formyl and 7-Hydroxymethyl Benzonorbornadienes.}

\author{
Ronald N. Warrener*, Geoffrey J. Collin and Patrick J. Foley \\ Centre for Molecular Architecture, Central Queensland University, North Rockhampton, 4701, \\ Queensland, Australia; FAX +61 749309917 Voice mail +61 749309845
}

*Author to whom correspondence should be addressed; E-mail r.warrener@cqu.edu.au

Received: 30 November 2000; in revised form 16 January 2001 / Accepted: 16 January 2001/ Published:

\begin{abstract}
Acetoxymethylidene)benzonorbornadiene 3, prepared in one step by the addition of benzyne to 6-acetoxyfulvene 2 , is hydrolysed in acid solution to form a 3:2epimeric mixture of syn- and anti- 7-formylbenzonorbornadienes 4 and 5, respectively; the corresponding 7-hydroxymethylbenzonorbornadienes 6 and 9 were produced by reduction of the formyl isomers with sodium borohydride.
\end{abstract}

Keywords: Benzyne, cycloaddition, enolacetates, fulvenes, benzonorbornadienes.

\section{Introduction}

7-Substituted benzonorbornadienes are important reagents, yet simple routes for their synthesis are lacking. In principle, such compounds can be prepared by addition of benzyne to 5-substituted cyclopenta-1,3-dienes, however these isomers are themselves very unstable, being converted to the more stable 2-substituted and 3-substituted isomers during the course of benzyne addition. Further, the addition of benzyne to cyclopenta-2,4-dienones, which would circumvent the substrate isomerisation problem and provide a carbonyl group in the 7-position for subsequent modification, is 
frustrated by the thermal instability of benzonorbornadien-7-ones [1]. Benzyne additions to cyclopentadienyl anions [2] and cyclopentadiene ketals [3-6] have been reported and have been used to prepare 7-substituted benzonorbornadienes.

Our answer to this issue has been to use a fulvene reagent since they have a fixed structure and can carry latent functionality to the 7-position of benzonorbornadienes. Accordingly, we investigated the addition of benzyne to 6-acetoxyfulvene 2 [7] for the synthesis of 7-(1-acetoxymethylene)benzonorbornadiene $\mathbf{3}$, since hydrolysis of the enol acetate group should yield the versatile formyl derivatives 4 and 5 at the 7-position. Masking of the norbornene $\pi$-bond of 7 -(1-acetoxymethylene)benzonorbornadiene as a cycloadduct has the potential to yield products which should be capable of ozonolysis to form stable benzonorbornen-7-one derivatives suitable for $\mathrm{CO}$ modifications. These latter aspects have been described separately [8], while this paper concentrates on the preparation of the title compound, its hydrolysis to 7-formyl-benzonorbornadienes and reduction to the 7-hydroxymethyl derivatives.

\section{Results and Discussion}

The reaction of benzyne 1, generated from diazotisation of anthranilic acid [9], to 6-acetoxyfulvene 2 proceeded without significant deacetylation to form 7-(acetoxymethylidene)-benzonorbornadiene 3 in $45 \%$ yield (Scheme 1). The ${ }^{1} \mathrm{H}-\mathrm{NMR}$ of 3 confirmed the presence of the acetate group (methyl resonance at $\delta 2.40$ ), while the unsymmetrical nature of the structure was evident from the bridgehead protons which appeared as well separated resonances $(\delta 4.16,4.56)$. The aromatic and norbornene $\pi$-bond resonances overlapped to produce an unresolved multiplet at $\delta 6.80-7.40$. The resonance for the exocyclic vinylidene proton in 3 occurred as a singlet at $\delta 6.58$, considerably downfield from that observed for 7-methylidenebenzonorbornadiene 8 ( $\delta 4.12$ ), consistent with the electron-withdrawing capacity of the acetoxy substituent.

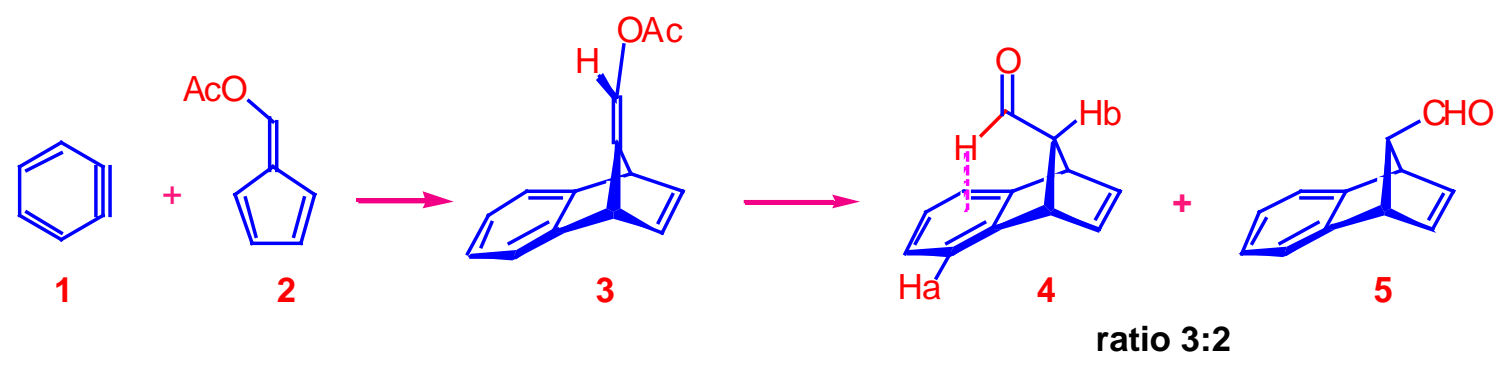

Scheme 1

Acid hydrolysis of $\mathbf{3}$ was conducted in acetone containing concentrated hydrochloric acid [10] and produced the syn-isomer 4 (stereochemical designations have been made relative to the benzene ring) and the anti-isomer 5 as an oily mixture (3:2, as determined by $\left.{ }^{1} \mathrm{H}-\mathrm{NMR}\right)$ in $69 \%$ yield. The individual isomers, which were separated by chromatography, each displayed a characteristic lowfield resonance for the aldehyde proton. Significantly, there was a difference of $0.42 \mathrm{ppm}$ in the chemical shifts of the two isomers, and this was used to help make their structure assignments. The 
higher field resonance $(\delta 9.18)$ of the major isomer 4 also displayed a vicinal coupling $(J=2.5 \mathrm{~Hz})$, which was not observed with its isomer 5 (slightly broadened singlet at $\delta 9.60$ ). The shift to high field of the major syn-isomer was consistent with the aldehyde being positioned above the benzenoid ring and this was confirmed by the presence of an NOE between the formyl proton and the aromatic proton $\mathrm{H}_{\mathrm{a}}$. The stabilisation afforded by the interaction of the formyl proton and the benzene ring fixed the formyl group in 4 in the transoid configuration. This proposal is supported by the $2.5 \mathrm{~Hz}$ coupling of the former proton with the bridge proton $\mathrm{H}_{\mathrm{b}}$. The lack of coupling in the anti-isomer 5 suggested that free rotation was occurring. Neither aldehyde could be obtained crystalline, so the syn-isomer 4 was converted to its pale yellow-coloured 2,4-dinitrophenyl hydrazone derivative for characterisation.

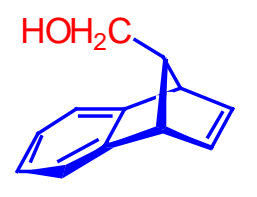

6

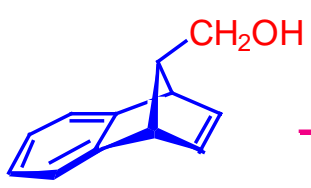

9
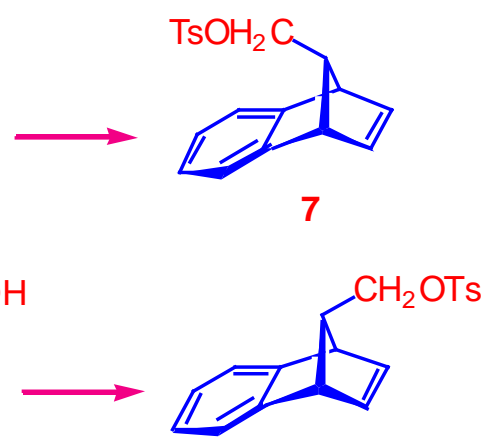

10

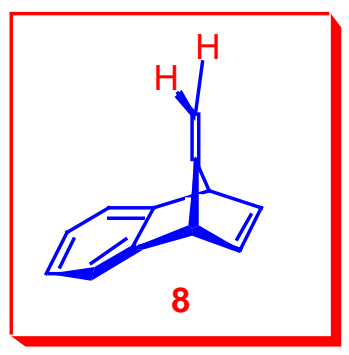

Scheme 2

Reduction of the aldehydes 4 and 5 to their respective hydroxymethyl compounds 6 and 9 was achieved in quantitative yield using sodium borohydride. When conducted on a mixture, the generated alcohols were separated by chromatography on silica and the syn-isomer 6 eluted first, suggesting there might be some H-bonding with the aromatic. In keeping with the assignments made for the aldehydes, the methylene protons of syn-isomer 6 occurred at higher field $(\delta 3.08)$ than the anti-isomer $9(\delta 3.60)$ which reflected the fact that the methylene protons were positioned closer to the shielding zone of the aromatic ring. The oily alcohol 6 was characterised as its 3,5-dinitrobenzoyl derivative [11].

Tosylation of a mixture of 6 and 9 was achieved by treatment with tosyl chloride in pyridine and formed a mixture of 7 and $\mathbf{1 0}$ that was recrystallised slowly from alcohol to yield two types of crystals. The larger prisms were shown to be the syn-isomer 7, while the colourless needles, which were separated manually from the mixture, corresponded to the anti-isomer $\mathbf{1 0 .}$

\section{BLOCK Coupling of Syn-7-hydroxymethyl-benzonorbornadiene 6.}

A special feature of the different isomers of the 7-hydroxymethyl-benzonorbornadienes $\mathbf{6}$ and 9 as substrates for BLOCK coupling reactions [12], is the accessibility of the $\pi$-bond for reagent attack at the exo-face. This difference is attributed to the screening effect of the hydroxymethyl group when it 
is on the same side as the $\pi$-bond (the anti-isomer 9) thereby precluding attack at that dienophilic centre. Thus, treatment of a mixture of alcohols 6 and 9 with the bis-epoxide 11 [13] gave only one coupled product 12, that derived from alcohol 6 , while unchanged alcohol 9 was recovered from the reaction mixture (Scheme 3). The structure of the coupled product 12 was supported by spectroscopy in which the bridge methine proton $(\delta 3.51)$ was typically downfield-shifted owing to its proximity to the adjacent oxabridge. The NOE between protons $\mathrm{H}_{\mathrm{a}}$ and $\mathrm{H}_{\mathrm{b}}$ fully confirmed the exo,exostereochemistry.

For molecule 12 to be an effective spacer system, then attachment of functionality at the hydroxymethyl groups must be easy to achieve. In this case, acylation of the pendant hydroxyl groups was readily achieved by acetylation with acetic anhydride containing sodium acetate as base, to thus form the diacetate 13 in $93 \%$ yield. This derivatisation is a marked improvement over spacer units in which the hydroxyl group is directly attached to the methano-bridge [14].

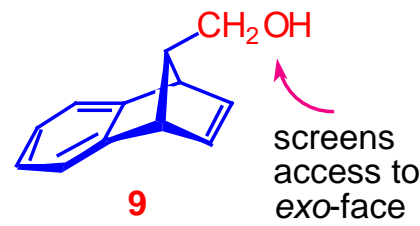

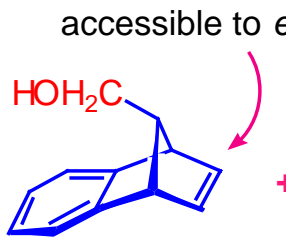

6 exo-face attack

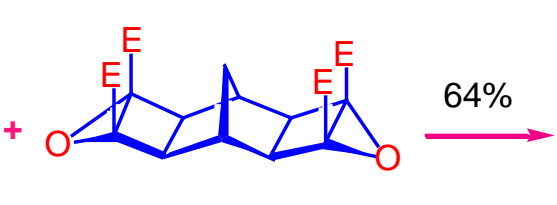

11

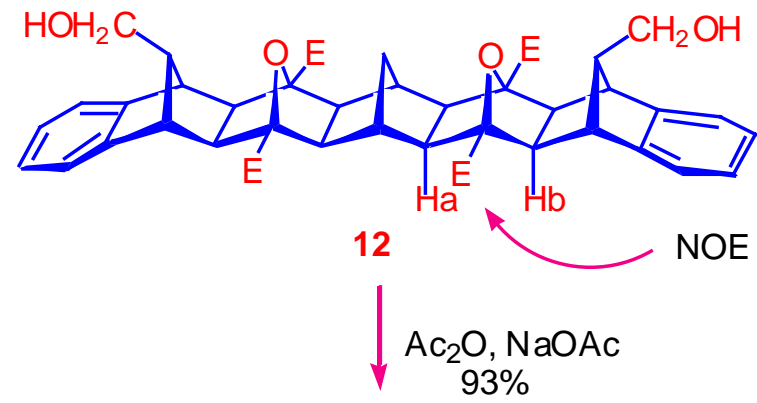

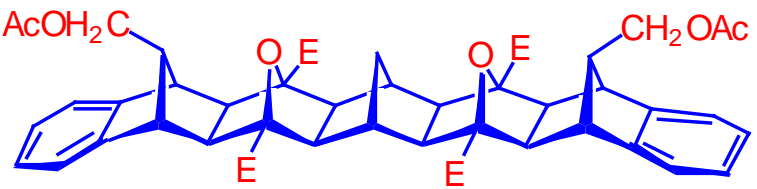

13

Scheme 3

\section{Conclusions}

A direct entry to 7-formyl benzonorbornadienes by hydrolysis of 7-(1-acetoxymethylene)benzonorbornadiene has provided access to a versatile set of syn-and anti-starting materials that can be readily transformed to other 7-substituted benzonorbornadienes, many of which are difficult to prepare by other methods. 


\section{Acknowledgements}

PF thanks CQU for the award of a PhD scholarship while GC acknowledges the award of a MSc scholarship from ANU. Funding support through the Centre for Molecular Architecture at CQU has enabled this work, which had its origins at ANU in the 1980s, to be completed. Several compounds described herein are presently being used in ARC-funded projects at CQU.

\section{Experimental}

\section{General}

Microanalyses were carried out by the ANU Microanalytical Service. Melting points, which are uncorrected, were determined with a Reichert melting point apparatus. IR spectra were recorded on a Unicam SP200G infrared spectrophotometer. UV spectra were recorded with a Unicam SP800 spectrophotometer. Mass spectra were recorded on a Varian Mat CH7 or an A.E. I. MS902 spectrometer. EI or ESMS (electrospray mass spectrometry) were conducted on a Micromass Platroem II single quadripole mass spectrometer. ${ }^{1} \mathrm{H}-\mathrm{NMR}(100 \mathrm{MHz})$ spectra were recorded on a Jeolco Minimar 100-MHz spectrometer. ${ }^{1} \mathrm{H}-\mathrm{NMR}$ (400 MHz) and ${ }^{13} \mathrm{C}-\mathrm{NMR}$ (75 MHz) were recorded on a Bruker Avance DPX 400-MHz spectrometer. All data was acquired using $\mathrm{CDCl}_{3}$ solutions with TMS as an internal standard and are reported in ppm on the appropriate $\delta_{\mathrm{H}}$ and $\delta_{\mathrm{C}}$ scales. Coupling constants are reported in Hz. The silica gel used for column chromatography was silica gel 60 (230400 mesh). TLC was performed on Merck aluminium sheets coated with silica gel $60 \mathrm{~F}_{254}$. Radial chromatography was carried out with a Chromatotron, Model No 7924T, using $1 \mathrm{~mm}$ plates coated with silica gel $60 \mathrm{~F}_{254}$. All preparative thin-layer chromatography was carried out on plates using 2 mm layers of silica gel $\left(\right.$ Merck $\left.\mathrm{GF}_{254}\right)$. All solvents were removed under reduced pressure.

\section{9-(Acetoxymethylidene)-1,4-dihydro-1,4-methanonaphthalene (3).}

Solutions of anthranilic acid $(55.4 \mathrm{~g}, 0.4 \mathrm{~mol})$ in tetrahydrofuran $(200 \mathrm{~mL})$ and isopentyl nitrite $(47.3 \mathrm{~g}, 0.4 \mathrm{~mol})$ in tetrahydrofuran $(200 \mathrm{~mL})$ were added dropwise and simultaneously to a refluxing solution of 6-acetoxyfulvene $(55 \mathrm{~g}, 0.4 \mathrm{~mol})$ in tetrahydrofuran $(100 \mathrm{~mL})$ over a period of about $1 \mathrm{~h}$. The solution was refluxed for a further $1 \mathrm{~h}$ cooled, made alkaline with aqueous sodium hydroxide $(4 \%, 500 \mathrm{~mL})$, and extracted with petroleum spirit $(3 \times 500 \mathrm{~mL})$. The dried extracts were freed of solvent and the residue recrystallised from n-hexane to yield the title product as pale yellow crystals (38 g, 45\%), m.p. $78-79{ }^{\circ} \mathrm{C}$; Found: C, 79.2; H, 5.8. $\mathrm{C}_{14} \mathrm{H}_{12} \mathrm{O}_{2}$ requires C, 79.2; H, 5.7\%; ${ }^{1} \mathrm{H}-\mathrm{NMR}$ (100 MHz): 2.40 (s, 3H, $\mathrm{CH}_{3}$ ), 4.16 (br m, 1H, bridgehead), 4.56 (br m, 1H, bridgehead), 6.58 (s, 1H, methylene proton), 6.80-7.40 (m, 6H, aromatic and $\left.\mathrm{H}_{2,3}\right)$; $\mathrm{UV}$ (ethanol) $\mathrm{nm}$ : (ع) 225 (3950), 265 (680), 272 (850), 279 (800); IR (nujol) $\mathrm{cm}^{-1}: 1080,1740 ; \mathrm{MS}: \mathrm{m} / \mathrm{z} 212\left(\mathrm{M}^{+}, 25 \%\right), 171(10), 170$ (72), 169 (66), 152 (12), 142 (41), 141 (100), 140 (10), 139 (25), 116 (19), 115 (53), 63 (10), 43 (51). The other peaks were less than $10 \%$. 


\section{Syn- and anti- 9-Formyl-tricyclo[6.2.1.0 $\left.0^{2,7}\right]$ undeca-2,4,6,9-tetraene $(4,5)$.}

A solution of enol acetate 3 ( $2 \mathrm{~g}, 9.4 \mathrm{mmol})$ in concentrated hydrochloric acid (4 mL) and acetone $(16 \mathrm{~mL})$ was refluxed for $0.5 \mathrm{~h}$. After cooling, water $(20 \mathrm{~mL})$ was added and the mixture extracted with ether $(2 \times 20 \mathrm{~mL})$. The ethereal extract was washed with water $(30 \mathrm{~mL})$, dried and freed of solvent. The ${ }^{1} \mathrm{H}-\mathrm{NMR}$ spectrum of the crude product indicated a 3:2 mixture of the syn-isomer 4 and anti-isomer 5. The residue was distilled (approx. $80^{\circ} \mathrm{C}, 0.1 \mathrm{mbar}$ ) to give the products as a colourless liquid $(1.1 \mathrm{~g}, 69 \%)$. The two isomers were separated by preparative TLC (silica, 1:1 chloroform and petroleum spirit).

The syn-aldehyde 4, was recovered from the least polar band as a colourless oil $(0.4 \mathrm{~g}, 25 \%)$. ${ }^{1} \mathrm{H}-\mathrm{NMR}$ (100 MHz): 3.25 (m, 1H, H $\mathrm{H}_{11}$ ), 4.15 (m, 2H, H $\mathrm{H}_{1,8}$ ), 6.88 (t, 2H, H 9,10), 6.90-7.40 (m, 4H, aromatic protons), $9.18\left(\mathrm{~d}, 1 \mathrm{H}, J=2.5 \mathrm{~Hz}\right.$, formyl proton); IR (nujol) $\mathrm{cm}^{-1}: 1730 \mathrm{~cm}^{-1}$ (carbonyl stretch); MS: $m / z 170$ (M+, 50\%), 169 (17), 142 (16), 141 (100), 115 (41), 63 (12), 21 (45). The other peaks were less than $10 \%$.

The 2,4-dinitrophenylhydrazone derivative was recrystallised from ethyl acetate giving bright yellow crystals, m.p. $177-178{ }^{\circ} \mathrm{C}$; Found: $\mathrm{C}, 61.7 ; \mathrm{H}, 4.0 ; \mathrm{N}, 15.9 . \mathrm{C}_{18} \mathrm{H}_{14} \mathrm{O}_{4} \mathrm{~N}_{4}$ requires $\mathrm{C}, 61.7 ; \mathrm{H}$, $4.0 ; \mathrm{N}, 16.0 \%$

The anti-aldehyde 5 was recovered as a colourless oil $(0.2 \mathrm{~g}, 12 \%) ;{ }^{1} \mathrm{H}-\mathrm{NMR}(100 \mathrm{MHz}): 3.20$ (m, 1H, $\left.\mathrm{H}_{11}\right), 4.20\left(\mathrm{~m}, 2 \mathrm{H}, \mathrm{H}_{1,4}\right), 6.74\left(\mathrm{t}, 2 \mathrm{H}, \mathrm{H}_{9,10}\right), 6.9-7.4(\mathrm{~m}, 4 \mathrm{H}$, aromatic protons), 9.60 (br s, 1H, formyl proton); IR (nujol) $\mathrm{cm}^{-1}: 1725 \mathrm{~cm}^{-1}$ (carbonyl stretch); MS: $m / z, 170\left(\mathrm{M}^{+}, 12 \%\right), 169$ (11), 142 (16), 141 (100), 115 (26). The other peaks were less than $10 \%$.

\section{Syn- and anti- 9-(hydroxymethyl)-tricyclo[6.2.1.0 $\left.0^{2,7}\right]$ undeca-2,4,6,9-tetraene $(6,9)$.}

A mixture of the syn-aldehyde 4 and anti-aldehydes $5(0.6 \mathrm{~g}, 3.5 \mathrm{mmol})$ in the ratio of $3: 2$ and sodium borohydride $(0.2 \mathrm{~g}, 6.7 \mathrm{mmol})$ were stirred in ethanol $(10 \mathrm{~mL})$ for $1 \mathrm{~h}$. Water was added and the solution extracted with ether. The ethereal extracts were dried, the solvent removed and the residual mixture of alcohols separated by preparative thin-layer chromatography (silica, $7 \%$ ethyl acetate in petroleum spirit, 10 developments).

The syn-alcohol 6 was recovered from the least polar band as a colourless liquid $(0.25 \mathrm{~g}, 42 \%)$. ${ }^{1} \mathrm{H}-\mathrm{NMR}(100 \mathrm{MHz}): 2.50$ (br s, 1H, OH), 2.84 (t, $\left.1 \mathrm{H}, J=8 \mathrm{~Hz}, \mathrm{H}_{11}\right), 3.08$ (d, $2 \mathrm{H}, J=8 \mathrm{~Hz}, \mathrm{OCH}_{2}$ ), 3.67 ( $\left.\mathrm{m}, 2 \mathrm{H}, \mathrm{H}_{1,8}\right), 6.80\left(\mathrm{t}, 2 \mathrm{H}, \mathrm{H}_{9,10}\right), 6.9-7.5$ ( $\mathrm{m}, 4 \mathrm{H}$, aromatic protons).

The 3,5-dinitrobenzoyl derivative was recrystallised again from a mixture of benzene and petroleum spirit (twice) to give pale yellow crystals, m.p. $137-140{ }^{\circ} \mathrm{C}$; Found: $\mathrm{C}, 62.6 ; \mathrm{H}, 4.1$; N, 7.7. $\mathrm{C}_{19} \mathrm{H}_{14} \mathrm{O}_{6} \mathrm{~N}_{2}$ requires $\mathrm{C}, 62.3 ; \mathrm{H}, 3.9 ; \mathrm{N}, 7.7 \%$

The anti-alcohol 9 was recrystallised from a mixture of benzene and petroleum spirit as white needles $(0.15$ g, $25 \%)$ m.p. $50-51.5{ }^{\circ} \mathrm{C}$; Found: $\mathrm{C}, 83.1$; H, 7.5. $\mathrm{C}_{12} \mathrm{H}_{12} \mathrm{O}$ requires $\mathrm{C}, 83.7 ; \mathrm{H}, 7.0 \%$ ${ }^{1} \mathrm{H}-\mathrm{NMR}(100 \mathrm{MHz}): 2.65$ (br s, $\left.1 \mathrm{H}, \mathrm{OH}\right), 2.80\left(\mathrm{t}, 1 \mathrm{H}, J=8 \mathrm{~Hz}, \mathrm{H}_{11}\right), 3.60\left(\mathrm{~d}, 2 \mathrm{H}, J=8 \mathrm{~Hz}, \mathrm{OCH}_{2}\right)$, $3.76\left(\mathrm{~m}, 2 \mathrm{H}, \mathrm{H}_{1,8}\right), 6.58\left(\mathrm{t}, 2 \mathrm{H}, \mathrm{H}_{9,10}\right), 6.8-7.3$ (m, 4H, aromatic protons); UV (ethanol) $\mathrm{nm}$ : (ع) 274 (430), 267 (500), 260 (430), 235 (930), 213 (4500); IR (nujol) $\mathrm{cm}^{-1}$ : 695, 735, 1010, 1020, 3300; MS: 
m/z $172\left(\mathrm{M}^{+}, 35 \%\right), 154$ (18), 153 (16), 142 (17), 141 (100), 129 (11), 128 (33), 115 (32). The other peaks were less than $10 \%$.

Syn- and anti- 9-(tosyloxymethyl)-tricyclo[6.2.1.0 $\left.0^{2,7}\right]$ undeca-2,4,6,9-tetraene $(7,10)$.

A solution of the syn-alcohol 6 and anti-alcohol $9(0.4 \mathrm{~g}, 2.3 \mathrm{mmol})$ in the ratio of 3:2 and tosyl chloride $(0.36 \mathrm{~g}, 1.9 \mathrm{mmol})$ in anhydrous pyridine $(3 \mathrm{~mL})$ was stirred under nitrogen for 3 days. Water $(10 \mathrm{~mL})$ was added and the solution extracted with ether $(3 \times 5 \mathrm{~mL})$. The combined ethereal extract was dried and freed of solvent. The residue was allowed to slowly crystallise from ethanol over a period of several days giving two crystal forms which were separated manually.

The syn-tosylate 7 , crystallised as large, colourless prisms $(0.25 \mathrm{~g}, 33 \%)$ m.p. $106-108{ }^{\circ} \mathrm{C}$. Found $\mathrm{C}, 69.9 ; \mathrm{H}, 5.5 ; \mathrm{S}, 9.8 . \mathrm{C}_{19} \mathrm{H}_{18} \mathrm{O}_{3} \mathrm{~S}$ requires $\mathrm{C}, 69.9 ; \mathrm{H}, 5.6 ; \mathrm{S}, 9.8 \% ;{ }^{1} \mathrm{H}-\mathrm{NMR}(100 \mathrm{MHz}): 2.48$ (s, $3 \mathrm{H}, \mathrm{CH}_{3}$ ), 3.04 (br t, $\left.1 \mathrm{H}, J=7.5 \mathrm{~Hz}, \mathrm{H}_{11}\right), 3.62$ (d, 2H, $\left.J=7.5 \mathrm{~Hz}, \mathrm{CH}_{2}\right), 3.72\left(\mathrm{~m}, 2 \mathrm{H}, \mathrm{H}_{1,8}\right), 6.88$ (t, $\left.2 \mathrm{H}, \mathrm{H}_{9,10}\right), 6.96-7.74$ (m, 8H, aromatic protons); UV (ethanol) nm: (ع) 274 (440), 269 (530), 227 (10000), 213 (9300); IR (nujol) cm $\mathrm{cm}^{-1}$ : 660, 700, 765, 835, 955, 1175; MS: m/z $326\left(\mathrm{M}^{+}, 28 \%\right), 155$ (23), 154 (100), 153 (31), 152 (10), 142 (14), 141 (99), 128 (25), 115 (26), 91 (25). The other peaks were less than $10 \%$.

The anti-tosylate 10, crystallised as colourless needles (0.15 g, 20\%) m.p. 105-105 ${ }^{\circ} \mathrm{C}$; Found: C, 69.8; H, 6.0; S. 9.5. $\mathrm{C}_{19} \mathrm{H}_{18} \mathrm{O}_{3} \mathrm{~S}$ requires C, 69.9; H, 5.6; S, 9.8\%; ${ }^{1} \mathrm{H}-\mathrm{NMR}(100 \mathrm{MHz}$ ): 2.48 (s, 3H, $\left.\mathrm{CH}_{3}\right), 2.96\left(\mathrm{t}, 1 \mathrm{H}, \mathrm{H}_{11}\right), 3.78\left(\mathrm{~m}, 2 \mathrm{H}, \mathrm{H}_{1,8}\right) 4.16\left(\mathrm{~d}, 2 \mathrm{H}, J=7.5 \mathrm{~Hz}, \mathrm{CH}_{2}\right), 6.58\left(\mathrm{t}, 2 \mathrm{H}, \mathrm{H}_{9,10}\right), 6.90$ 7.84 (m, 8H, aromatic protons); UV (ethanol) nm: (ع) 274 (460), 269 (610), 226 (11400), 221 (14300); IR (nujol) $\mathrm{cm}^{-1}:$ 950, 1175; MS: $\mathrm{m} / \mathrm{z} 326\left(\mathrm{M}^{+}, 21 \%\right), 155$ (22), 154 (100), 153 (36). 152 (10), 142 (12), 141 (81), 128 (28), 115 (28), 91 (29), 65 (15). The other peaks were less than $10 \%$.

\section{The tosylhydrazone of 9-formyl-tricyclo[6.2.1.0 $\left.0^{2,7}\right]$ undeca-2,4,6,9-tetraene (4).}

A solution of the syn-aldehyde $4(0.5 \mathrm{~g}, 2.90 \mathrm{mmol})$ and $N$-tosylhydrazine $(0.54 \mathrm{~g}, 2.9 \mathrm{mmol})$ in methanol $(10 \mathrm{~mL})$ containing two drops of concentrated hydrochloric acid was stirred for $1 \mathrm{~h}$. The solvent was removed and the product dissolved in hot benzene $(20 \mathrm{~mL})$. On cooling the excess $N$-tosylhydrazine was removed by filtration and the filtrate freed of solvent. The residue was recrystallised from ethanol to give the product as colourless needles $(0.6 \mathrm{~g}, 61 \%)$ m.p. $134-135{ }^{\circ} \mathrm{C}$. Found: C, 67.4; $\mathrm{H}, 5.7 ; \mathrm{N}, 8.2 ; \mathrm{S}, 9.5 . \mathrm{C}_{19} \mathrm{H}_{18} \mathrm{~N}_{2} \mathrm{SO}_{2}$ requires $\mathrm{C}, 67.4 ; \mathrm{H}, 5.4 ; \mathrm{N}, 8.3 ; \mathrm{S}, 9.5 \%$; ${ }^{1} \mathrm{H}-$ NMR (100 MHz): 2.44 (s, 3H, CH $\mathrm{CH}_{3}, 3.40$ (dd, 1H, $\left.\mathrm{H}_{11}\right), 3.88\left(\mathrm{~m}, 2 \mathrm{H}, \mathrm{H}_{1,8}\right), 6.50$ (d, 1H, $\left.\mathrm{H}_{\mathrm{a}}\right), 6.84$ (m, $2 \mathrm{H}, \mathrm{H}_{9,10}$ ), 6.8-7.8 (m, 8H, aromatic protons); UV (ethanol) nm: (ع) 276 (1000), 271 (1500), 244 (7800); IR (nujol) cm $\mathrm{cm}^{-1}: 1165,1360 ; \mathrm{MS}: \mathrm{m} / \mathrm{z} 338$ (M+, 5\%), 184 (15), 183 (100), 167 (17), 166 (27), $156(16), 153$ (15), 152 (13), 141 (10), 129 (11), 128 (25), 115 (15), 91 (17). The other peaks were less than $10 \%$.

Tetramethyl (1 $\alpha, 2 \beta, 3 \alpha, 4 \beta, 5 \alpha, 12 \alpha, 13 \beta, 14 \alpha, 15 \beta, 16 \alpha, 17 \beta, 18 \alpha, 19 \beta, 20 \alpha, 27 \alpha, 28 \beta, 29 \alpha, 30 \beta) 32,34-$ dioxa- 33,35-dihydroxymethyldodecacyclo $\left[14.14 \cdot 1 \cdot 1^{3,14} \cdot 1^{5,12} \cdot 1^{18,29} \cdot 1^{20,27} \cdot 0^{2,15} \cdot 0^{4,13} \cdot 0^{6,11} \cdot 0^{17,30} \cdot 0^{19,28}\right.$ - 


\section{$\left.0^{21,26}\right]$ pentatriaconta-6,8,10,21,23,25-hexaene-3,14,18,29-tetracarboxylate (12).}

A mixture of alcohol mixture 6 and 9 (syn:anti $=2: 1),(168 \mathrm{mg}, 0.98 \mathrm{mmol})$ and bis-epoxide 11 $(133 \mathrm{mg}, 0.33 \mathrm{mmol})$ was dissolved in acetonitrile $(5.0 \mathrm{~mL})$ and transferred to a thick-walled glass tube which was cooled, sealed and placed in an oven at $140{ }^{\circ} \mathrm{C}$ for $3.5 \mathrm{~h}$. After evaporation of the solvent under reduced pressure, the crude product was purified by radial chromatography. Elution using a solvent system of petroleum ether : $E t O A c=1: 3$ gave unreacted anti-alcohol 9. Increasing the polarity to $\mathrm{MeOH}: \mathrm{EtOAc}=1: 9$ afforded 12 as a colourless solid (156 mg, 64\%), m.p. 221-223 ${ }^{\circ} \mathrm{C}$. ${ }^{1} \mathrm{H}-\mathrm{NMR}$ (400 MHz): 1.83 (s, 4H, H2,15,17,30), 1.95 (br s, 2H, H31), 2.08 (br s, 2H, $\mathrm{H}_{1,16}$ ), 2.15 (s, $\left.4 \mathrm{H}, \mathrm{H}_{4,13,19,28}\right), 3.05$ (d, 4H, J = 6.9 Hz, $\left.\mathrm{H}_{1^{\prime}, 2^{\prime}}\right), 3.09$ (s, 4H, $\left.\mathrm{H}_{5,12,20,27}\right), 3.45$ (t, 2H, J = 7.3 Hz, $\mathrm{H}_{33,35}$ ), $3.91\left(\mathrm{~s}, 12 \mathrm{H}, \mathrm{OCH}_{3}\right), 7.05-7.08\left(\mathrm{~m}, 4 \mathrm{H}, \mathrm{H}_{8,9,23,24}\right), 7.10-7.13\left(\mathrm{~m}, 4 \mathrm{H}, \mathrm{H}_{7,10,22,25}\right) ;{ }^{13} \mathrm{C}-\mathrm{NMR}(75 \mathrm{MHz})$ : $28.88\left(\mathrm{C}_{31}\right), 40.65\left(\mathrm{C}_{1,16}\right), 47.53\left(\mathrm{C}_{5,12,20,27}\right), 52.33\left(\mathrm{OCH}_{3}\right), 55.31\left(\mathrm{C}_{33,35}\right), 55.31\left(\mathrm{C}_{2,15,17,30}\right), 56.24$ $\left(\mathrm{C}_{4,13,19,28}\right), 61.04\left(\mathrm{C}_{1^{\prime}, 2^{\prime}}\right), 89.39\left(\mathrm{C}_{3,14,18,29}\right), 122,19\left(\mathrm{C}_{7,10,22,25}\right), 126.42\left(\mathrm{C}_{8,9,23,24}\right), 145.43\left(\mathrm{C}_{6,11,21,26}\right)$, 169.20 (carbonyl) . HRMS (EI) for $\mathrm{C}_{43} \mathrm{H}_{44} \mathrm{O}_{12}$ Calc. 752.2833; Found 752.2833.

Tetramethyl (1 $\alpha, 2 \beta, 3 \alpha, 4 \beta, 5 \alpha, 12 \alpha, 13 \beta, 14 \alpha, 15 \beta, 16 \alpha, 17 \beta, 18 \alpha, 19 \beta, 20 \alpha, 27 \alpha, 28 \beta, 29 \alpha, 30 \beta) 32,34-$ dioxa-33,35-diacetoxymethyldodecacyclo $\left[14.14 \cdot 1 \cdot 1^{3,14} \cdot 1^{5,12} \cdot 1^{18,29} \cdot 1^{20,27} \cdot 0^{2,15} \cdot 0^{4,13} \cdot 0^{6,11} \cdot 0^{17,30} \cdot 0^{19,28}\right.$ $\left.0^{21,26}\right]$ pentatriaconta-6,8,10,21,23,25-hexaene-3,14,18,29-tetracarboxylate (13).

A solution of diol $12(70 \mathrm{mg}, 0.09 \mathrm{mmol})$, acetic anhydride $(300 \mu \mathrm{L}, 2.9 \mathrm{mmol})$ and sodium acetate $(7 \mathrm{mg}, 0.08 \mathrm{mmol})$ in chloroform $(5.0 \mathrm{ml})$ was refluxed for $4 \mathrm{~h}$. The reaction mixture was allowed to cool and poured onto cold water $(8 \mathrm{ml})$. The organic layer was washed with sodium bicarbonate (saturated solution), $(2 \times 8 \mathrm{ml})$, dried $\left(\mathrm{MgSO}_{4}\right)$, and concentrated by removal of solvent under reduced pressure. The crude product was recrystallised from methanol as a colourless solid; yield: $72 \mathrm{mg}$, (93\%), mp 245-247 ${ }^{\circ} \mathrm{C} ;{ }^{1} \mathrm{H}-\mathrm{NMR}$ (400 MHz): 1.84 (s, 4H, $\mathrm{H}_{2,15,17,30)}$ ) 1.93 (s, 6H, OAc), 1.95 (br s, 2H, H ${ }_{31}$ ), 2.10 (br s, 2H, $\mathrm{H}_{1,16}$ ), 2.15 (s, 4H, $\mathrm{H}_{4,13,19,28}$ ), 3.07 (s, 4H, H $\mathrm{H}_{5,12,20,27}$ ), 3.51 (m, 6H, H $\left.\mathrm{1}^{\prime}, 2^{\prime}, 33,35\right), 3.92$ (s, 12H, $\mathrm{OCH}_{3}$ ), 7.05-7.07 (m, 4H, $\mathrm{H}_{8,9,23,24}$ ), 7.09-7.12 (m, 4H, $\mathrm{H}_{7,10,22,25}$ ); ${ }^{13} \mathrm{C}-\mathrm{NMR}$ (75 MHz): 20.76 (OAc), $28.87\left(\mathrm{C}_{31}\right), 40.62\left(\mathrm{C}_{1,16}\right), 48.00\left(\mathrm{C}_{5,12,20,27}\right), 51.64\left(\mathrm{C}_{33,35}\right), 52.29$ $\left(\mathrm{OCH}_{3}\right), 55.24\left(\mathrm{C}_{2,15,17,30}\right), 56.21\left(\mathrm{C}_{4,13,19,28}\right), 63.10\left(\mathrm{C}_{1^{\prime}, 2^{\prime}}\right), 89.38\left(\mathrm{C}_{3,14,18,29}\right), 122,29\left(\mathrm{C}_{7,10,22,25}\right)$, $126.67\left(\mathrm{C}_{8,9,23,24}\right), 145.01\left(\mathrm{C}_{6,11,21,26}\right), 169.15,170.77$ (carbonyl); HRMS (ES) for $\left[\mathrm{C}_{47} \mathrm{H}_{48} \mathrm{O}_{14}+\mathrm{Na}\right]^{+}$ Calc. 859.2942; Found 859.2945.

\section{References}

1. a) Birney, D. M.; Berson, J. A. Synthesis of the Covalent Benzene-Carbon Monoxide Cycloadduct, Norborna-2,5-Dien-7-One. Correlation of Kinetic and Thermodynamic Stabilities in Cycloreversion Reactions. Tetrahedron, 1986, 42, 1561-1570.

2. Plummer, B. F.; Currey, J. A.; Russell, S. J.; Steffen, L. K.; Watson, W. H.; Bourne, S. A. The Synthesis and X-Ray crystallographic Analysis of a Stable Norbornadienone: 17-Oxo-7,16- 
Methano-7,16-Diphenylcyclopenta[d,e]tribenzo[a,h,j]anthracene. Struct. Chem. 1995, 6, 167173.

3. Warrener, R. N.; Pitt, I. G.; Russell, R. A. Reactions of Dienophiles with a 5,6-Bismethylenenorborn-2-en-7-one: the Synthesis of a Stable Norborna-2,5-dien-7-one. Aust. J. Chem. 1993, 46, 1009-1019.

4. LeBlanc, B. F.; Sheridan, R. S. Photochemical Generation and Direct Observation of 7-Norbornadienone. J. Am. Chem. Soc. 1985, 107, 4554-4556.

5. Buske, G. R.; Ford, W. T. Additions and Cycloadditions of Cyclopentadienyl Metal Compounds to Benzyne. J. Org. Chem. 1976, 41, 1995-1998.

6. Wilt, J. W.; Vasiliauskas, E. Studies of Benzonorbornene and Derivatives. 5. Adduction of Benzyne with 5,5-Dimethoxy-1,2,3,4-tetrachlorocyclopentadiene. J. Org. Chem. 1970, 35, 2410-2411.

7. Hafner, K.; Schulz, G.; Wagner, K. 6-Amino-Sowie 6-Hydroxy-Fulvene und deren AzaAnaloga. Justus Liebigs Ann. Chem. 1964, 678, 39-53.

8. Warrener, R. N.; Collin, G. J., unpublished results

9. Friedman, L.; Logullo, F. M. Benzynes via Aprotic Diazotization of Anthranilic Acids: A Convenient Synthesis of Triptycene and Derivatives. J. Am. Chem. Soc. 1963, 85, 1549.

10. Brown, E. D.; Clarkson, R.; Leeney, T. J.; Robinson, G. E. Acetoxyfulvene Synthesis of Prostaglandins: an Alternative Synthesis of the Corey Aldehyde. J. Chem. Soc., Chem. Commun., 1974, 642.

11. Ongley, P. A. Organicum. Pergamon Press, 1973; p 426.

12. Warrener, R. N.; Butler, D. N.; Russell, R. A. Fundamental Principles of BLOCK Design and Assembly in the Production of Large, Rigid Molecules with Functional Units (Effectors) Precisely Located on a Carbocyclic Framework. Synlett, 1998, 566-573.

13. Warrener, R. N.; Schultz, A. C.; Butler, D. N.; Wang, S.; Mahadevan, I. B.; Russell, R. A. A New Buillding BLOCK Technique based on Cycloaddition Chemistry for the Regiospecific Linking of Alicyclic Sub-Units as a Route to Large, Custom-Functionalised Structures. J. Chem. Soc. Chem. Commun., 1997, 1023-1024.

14. Warrener, R. N.; Groundwater, P.; Pitt, I. G.; Butler, D. N.; Russell, R. A. The Synthesis of Spacer Molecules Containing an Alcohol Group at each Terminus. Tetrahedron Lett., 1991, 32 1885-1888.

Sample Availability: Samples not available.

(C) 2001 by MDPI (http://www.mdpi.org). Reproduction is permitted for noncommercial purposes 